\title{
A Dissertation on the Personalization Features of Freud's Painting Language
}

\author{
Shaojie Zhang \& Jing xi \\ Zhengzhou Huaxin University, Xinzheng, Zhengzhou
}

\begin{abstract}
Lucian Freud is one of the representative artists in the field of contemporary realism painting field. Freud's painting language and image expression of its own style that has a great influence on the contemporary realism painting. His works reach a perfect unification in the texture and structure, space, volume, color painting factors. the picture shows a unique aesthetic value to people. The works have a highly personalized style. Freud's paintings have profound meaning to the spread of the traditional realistic painting, it also has progressive significance to the development of modern art.
\end{abstract}

KEYWORD: Realism painting; Expression; Personalized

\section{INTRODUCTION}

With the development of western modern painting, all kinds of painting are colorful. Freud is insist committed to the research of realistic painting. He discribe the state of modern people, formed a unique "freudian" spirit of the painting language. This article attempts to express the spirit of the emotionas in contemporary realism painting language and the unique personalized features through the introduction of Freud's resume, the development of artistic style, and its personalized style characteristics.

Freud's realism painting has great historic significance. On the one hand,it heritage the European classical realism painting. On the other hand, it breakthrough the realism painting and inject fresh blood of the modernism. Freud's painting is beneficial for the transmission of traditional realistic painting, also has progressive significance to the development of modern art. This article through of the Freud painting language and the analysis of characteristics of personalization to further understand and study modern realism painting.

\section{ART RESUME AND BACKGROUND}

\subsection{Freud's artistic resume}

Born in Vienna in 1922 of a jewish family. His grandfather is Sigmund Freud that a famous psychologist. He is a child has natural suspicion, lonely and curious spirit that make his unease, perception of the world that keep a special perception ability. This perception ability will be brought into the picture, become his own bright symbol.

Freud into st union painting school in 1939, trained bythe principal morris. This time his painting theme is broad that influence of surrealism. The painting is delicate and detail, then it began to have some sensitive.

From the $40 \mathrm{~s}$ to $80 \mathrm{~s}$, he settled in London, whether as an artist or ordinary people, Freud are supposed to be hard to get along with. $\mathrm{He}$ is in a state of isolated and un, he concentrate on his own field that away from the international trend of art.

In recent years, Lucian Freud held a personal exhibition for many times in Britain and the United States, his works is the highest price in London Christie's and sotheby's auction, so that he once again become the focus of the critics. Freud's painting "a sleeping benefits supervisor" be bought by a European collector on May 13, 2008 in New York for $\$ 33.64$ million, that became the most expensive living artist's works.

\subsection{The art influences of the family background}

Freud, as all educated Viennese family, his elders in his childhood environment and create a sense of Vienna - a suspicion and exploring spirit. In the Germanic languages, the lonely sensitive was born and the Austrian literary works often reflect the theme of the picking unstable molecules in the body of the shadow of roaming. As a famous 
psychologist, read his grandfather let young grandson quatrain \"song under the gallows।", in his paintings, hang on the living room..., all of this caused him to form a special kind of consciousness. By 1933, Lou Freud follow father moved to the UK, the Austrian became famous English painter. Lucian Freud's work before age 20 years almost all rely on direct observation of the material. At that time, the British English, is actually a Munich - has been warning of war frighten lifeless, people psychological stasis by inexplicable fear than the show the words and deeds. May be childhood personality cause, also may be he is sensitive to reality, the soul of his youth was two invisible line leads circuitous journey in feeling and dream.

\section{THE FORMATION OF FREUD'S PAINTING LANGUAGE}

\subsection{Previous art painting language style (40s to 50s)}

It is a slightly exaggerated form, partial key, line density contrast and composition technique, plane, have adornment style. He used this kind of gimmick painted many thorny plants and emotional indifference and strange characters of apprehension. While those with a nervous feeling line and shape by a specific tension. He said he was influenced by Beardsley, may also help us to know that his life is common in the works of those for graphic depiction of sex, it may be a lonely, mentality and ecological spirit need instinct interpretation of the flesh to himself. Freud's early works in some sense close to Schiller's work style, expressed anxiety slightly nervous and sensitive, stroke smooth, smooth and fine.

Early on behalf of I"take the girl rosel" (1947), the work presented the he can grasp details and good performance ability of nuanced QingSu Freud has the stable life. The frame, the girl sit slightly off center, broad shoulders motioned girl confident and independent personality traits. On the painting skills, Freud in the task of face, the use of clothing and chairs behind the seemingly flat technique of coating, brush excessive tender soft, almost can't see the brush strokes, in this kind of fine gentle brushwork floating color relieve slight change, make the person's face and clothing on the processing of delicate and subtle, volume is not very strong character. Images to express the relationship between space and the characters, but the overall effect is similar to the two type of picture. Another painting of his girl and a white dog, painter with tapering small character's hair and white dog fur, delicate transfer of difficult line in deep GouMiao body carry bright color of the hair impression, and each group of pen has a clear boundary line distinguished from another group of lines. Women are blond hair, pale green pajamas, as well as the white dog hair nuanced, very able to bear or endure look. The whole picture smooth tonal and downy, under the background of warm gray, white dog and light green clothes dressed woman appear lively and exquisite. Picture of the painting language is a little similar to traditional Chinese painting methods of dealing with the lyrics. Character's facial expressions and clothing with exquisite and hidden stroke smooth surface clean, character of the stereo sense is not strong, shadow, just for the sake of performance form is not to achieve the effect of classical oil painting space depth, on the whole tend to be more a feeling of complanation and decoration, the fine delicate, smooth as a mirror skin texture strokes, and the characters dull because of rigid strain modal together, the peace of the whole picture spread a kind of fright, appear this kind of brushwork texture processing has been injected with a painter for objective object is a kind of subjective experience and spiritual concern, rather than simply on meticulous and shortlisted for the objective object outgoing depict. Secrecy, careful, grinds to the delicate brushwork texture conveys the painter sensitive spirit temperament, at the same time, these works have preliminarily show Freud quiet, awe, indifference which personalized style.

\subsection{Late 2.2 the art of painting language style $(50 \mathrm{~s}$ yet)}

$50 \mathrm{~s}$, his painting style has changed a seems to be reborn, his line, plane, decoration, drawing, painting style, turned to the volume, space, realistic sense, trying to rely more oil painting color performance. His painting is sensitive to outline of neurotic, into the oil painting brush strokes charity decent more see the rational efforts to shape the form. Hidden in the works of his early adolescent pathological anxiety and tension, into a he who sees through the world, deep the feeling of helplessness and loneliness exhausted when. The magnanimous, exposed, callous flesh, in a kind of suffering by desire in the experience of pain. He had previously that contour sharp sensitive nervous become relaxation, but he has made a more intrinsic, more eruptions storage volume of storage to the sense of tension, which has intensified on the expression of shape and state that it surprised the audience visual impact. He put the super realistic style kept until now. Freud with rough and full of elasticity bristle pen instead of the early practical delicate soft sable brush, brush strokes to become more powerful and administrative levels sense, expressive and more intense. Has seen the formation and the early work is exquisite, instead, the brush strokes reveal the thick and strong crude, varied style to warm. Begin to shape the image directly with powerful strokes, according to the physique structure with a hard 
bristle pen to powerful sweep, ।"brush strokes with the structure of transshipment and traces of longl". The works of this period, Freud is no longer the hair carefully described as bird feather, characters of the skin, clothing and the background. Also don't like his early work not delicate brushwork, but with the bristle pen drive leave the natural texture of thick paint through the canvas to represent the simple sense of objects. This period and the shaping of the form of a solid, a strong sense of volume, and more is painting. Strong strokes the sketch and strengthening the structure, the combination of work has present a striking force. Robert hughes believes that Freud's this style change maybe from his friend Steve Francis Bacon unfettered than junior middle school to get some enlightenment. But I think this is just a kind of external cause, more important is the painter of spiritual needs, in the long term the creative activities of a choice, for their own goals in bacon's art pursue is to some extent for the freudian excitement of sensory nerve, beating and impressionist, scattered strokes, Freud's painting brush contains a force modelling aesthetic feeling, perhaps the impressionist jump, vibrant strokes is in pursuit of the vibrating of the amount of light and color, brushwork is more powerful in using paint create a solid form, from the late in a series of works we can see the painter pursuit stroke moment research as the transfer of physical structure, closely integrated with the form, accurately reflect the volume and space. Structure modelling factors such as internal relations, that is the beauty of Freud's pen. For example, a man in the green unlined upper garment, a painting, according to the structure characteristics of the head, the painter USES a circular shape, arch, the superciliary arches, cheekbones and jaw structure turns out to strengthen the exaggeration, handwriting along the direction of physical structure, accompanied by light, color, and make us feel the force of signs. Advantages of this kind of pen to strengthen let a person feel a bit, a little flower, but seen from the overall harmony. It is I often imagine that we often say that the structure of the sketch. As these strokes of trace, we seem to be able to see under the surface every muscle, every piece of blood vessels, each piece of bone real storage. The picture has a strong sense of approximation. In fact, Freud's pen is not only to solve the problem of object structure form, but also contain the harmony of the theme and objective factors. Chinese painting is very stressed xingshenjianbei, to write god HuaLi, Freud's art pursuit should be on the basis of shape and spirit, further magny cours, object, for me to dominate the brush with affection, the view of this object must have strong personal feelings color and unique artistic style.

\section{THE FORMATION OF FREUD'S PAINTING LANGUAGE}

\subsection{Colour modelling style works}

\subsection{1 image expression}

Freud's painting object never describe dramatic events, basically give priority to with indoor portrait, nude portrait. It also makes him become a painter. And he will be in the interior of close man took pains depict some near a nervous state, he likes the theme of the deformity and pathological. Freud is away from the hustle and bustle of the international trend of art, to excavating in depth direction, in the field of such large with real people or the whole up bi painting works were more significantly, the sitter as often have an unyielding stance, or head of inclined backward, life or both arms, the subjects lost in unprecedented vivid effect, have very strong visual impact and expressive force. Freud's work in realistic techniques of high degree of confidence, the clear enough physical structure, embodied in the rational expression of an appropriate response to harness. Freud in painting sketch recognition, so that he's morphology in volume, space contains modal perturbation of the object factor has a kind of abnormal tension. He used this kind of gimmick painted many thorny plants and emotional indifference and strange characters of apprehension. $\mathrm{He}$ is a special observation and expressive character sketch artist, in the image, in the human body, from the object on the basis of the understanding of the inner structure, find out the structure factors, body and face, muscle and fragments echo, connected to the composition of the relationship and situation. He put the object into a feeling of near building performance. The resulting in his painting language very unique modelling of a solid, solid like a building.

\subsection{2 the colour of life}

Freud said he didn't want people pay too much attention to the picture color, he is a kind of \"color $\backslash "$ of life. This has the same effect and van gogh to is. When his work into China, for many avant-garde artist. In painter and his contemporaries, I believe that no one can get a historic breakthrough like him. He worked for the British queen painted portraits, past the queen in the artist's hand all beauty of beautiful huan, but by freund's shelves, everything changed immediately flavour: on the queen's face is segmented into several large, bloated, skin look very old, no see no royal demeanor. But fortunately, this painting is in freund's old age, so coloring is relatively mild. Freud from the ninety s and soft in color, not as sick as ever. The reason is probably will go into old age stage. 


\subsection{Work brushwork texture}

Presented in the works of Freud, the dignified and decisive, exactly and stiffness and agile oil painting brush, closer to a language that shape. Is a kind of form is slightly exaggerated, partial key, line density contrast and composition technique, plane, have adornment style. In the painting of the thick, repeated overlapping strokes in the picture in the form of a specific ।"texturel" feeling of oil paints. Freud's brushwork texture from the early stiff stiff, indifference to mid thick full, strong strong and mature individual style, and then again in the late transitional change into deep, natural reservation.

\subsection{Emotional expression of the works}

Freud fulfilled by his lonely feelings, a kind of special spiritual world of emptiness. The naked, don't like but comfortable sense of reality, a painting is unique to the Freud's kingdom. When Freud called him the real attention to his portrait painting, his that kind of sensitive, nervous powers of observation and his unique rigorous expression on the sketch, to his sense of reality, really have the feeling of a more convincing. Lost the realistic interest of the contemporary western painting, Freud in portrait art with unique achievements in this territory, he has a realistic ability resembles the images of objects, but he paid more attention to in the portrait of human nature revealed hints. He simplified background that in most cases, to look into people's portrait, and always have a kind of forced audience visual effect. He figures that there with loneliness, in the air, also with some more doubt after cold helpless or fright, and together with a \"Freud's।" mental symptoms. Hidden in the works of his early adolescent pathological anxiety and tension, into a he who sees through the world, deep the feeling of helplessness and loneliness exhausted when. The magnanimous, exposed, callous flesh, in a kind of suffering by desire in the experience of pain.

\section{CONCLUSION}

Trend in today's diversified oil painting art development, contemporary Freud's realism painting, in the original realism painting developed its unique painting language and personalized features, with a strong painting and visual impact, bring realism painting historic significance.

\section{REFERENCES}

[1] William Feaver, LUCIAN FREUD (Freud), London: Tate Publishing Tatepublishing house, 2003

[2] Huang Jun, Freud art, jiangsu, jiangsu fine arts publishing house, 1998 